\title{
The State of State History: A Review Essay
}

\section{David B. Danbom}

The Indiana Way: A State History, by James H. Madison. Bloomington: Indiana University Press, 1986. xvii, 361 pp. Illustrations, charts, photographs, maps, appendixes, notes, bibliographical essay, index. $\$ 20.00$ cloth.

The History of Wisconsin, vol. 3, Industrialization and Urbanization, 1873-1893, by Robert C. Nesbit. Madison: State Historical Society of Wisconsin, 1985. xiii, 693 pp. Maps, photographs, charts, appendix, notes, bibliographical essay, index. $\$ 30.00$ cloth.

The History of Wisconsin, vol. 6, Continuity and Change, 1940-1965, by William F. Thompson. Madison: State Historical Society of Wisconsin, 1988. xiii, 830 pp. Illustrations, maps, photographs, charts, appendix, notes, bibliographical essay, index. $\$ 35.00$ cloth.

A History of Missouri, vol. 5, 1919 to 1953, by Richard S. Kirkendall. Columbia: University of Missouri Press, 1986. viii, 438 pp. Bibliographical essay, index. $\$ 28.00$ cloth.

THE PRACTICE of writing histories of states, widely predicted to be doomed as late as two decades ago, has undergone a renaissance in recent years. I am not sure why that is the case, but no doubt local pride and the growing desire of an aging population to learn about its roots have played a part. Another attraction of state history is that it is one of the few subjects remaining about which scholars in an increasingly professionalized and desiccated discipline can say anything that interests intelligent lay people. From a practical standpoint, W. W. Norton's decision to publish a history of each of the states in commemoration of the nation's bicentennial stimulated thinking and writing about state history.

THE ANNALS OF IOWA 50 (Spring 1990). (C) The State Historical Society of Iowa, 1990. 
Not only were fifty volumes turned out, but dozens of excluded state historians were stimulated to expand on or revise the Norton authors in works of their own, thereby injecting remarkable vitality into what had been rather a staid and stodgy enterprise.

The renewed genre of state history has changed a good deal since the days when it was mainly the province of pedestrian academics who focused on politics and economics, praised their states' heroes and ignored its villains, and saw what happened in it occurring more or less independently of events elsewhere. As the authors of the volumes reviewed in this essay illustrate, state history now commands the attention of nationally respected historians. Reflecting trends in American historiography in general, these new state historians have widened their focus to include society, demography, and culture, and to consider the special positions of women, blacks, native Americans, and other long neglected groups. Today's state historians are also more likely than their predecessors to frame their state and its activities in regional or national contexts.

The changes in state history have made it a much more challenging subject for scholars than it used to be. The fact that they are expected to be more synthetic and more sensitive to broad developments presents them with new organizational difficulties. Cultural, social, and demographic changes are not always well handled using the periodization with which historians are comfortable, leaning heavily as it does on wars, depressions, and political administrations. State historians also have to address the enduring problem of relating the state to the nation, of explaining the ways in which the state's experience was different and the ways in which it was similar to what was going on elsewhere in the country. This is related to the problem of identifying the "essence" of a particular state, of defining, if you will, what is so special about this particular political abstraction imposed on the North American landscape by congressmen and cartographers. And state historians have to do all of this in such a way as to be credible to the hundreds of local chauvinists who have their own firmly held convictions about the state in which they live.

Of the volumes under review in this essay, James Madison's Indiana Way best fulfills the varied requirements of a good contemporary state history. The Indiana Way is a comprehensive treatment of the state's past, beginning with its geological and na- 
tive American prehistory and concluding with its present in about 320 pages of text. Madison's organization is one of topical chapters within broad chronological sections. Such a format allows him to hit most of the high points of Indiana's history without excessive repetition.

Madison is especially strong in defining the Hoosier character, or, as he puts it, "the Indiana way." He believes Indianans demonstrate rural and small-town values, even though their state is part of America's heavy industrial heartland. He finds that Hoosiers put a premium on moderation and tradition and demonstrate a strong sense of community arising at least in part from ethnic, racial, and religious homogeneity. He also finds them strongly committed to individual self-reliance and minimal government, though, a bit paradoxically perhaps, they are also intensely partisan.

There are flaws in The Indiana Way. At times Madison seems to see developments in Indiana in a context that is too narrow, and he is weaker on the earlier period than he is on the later period of Hoosier history. There are points at which he excuses too much or engages in some special pleading, but that flaw is endemic in state histories. What is best about The Indiana Way is that it gives the non-Hoosier reader a convincing picture of the state and what is unique about it. One cannot reasonably ask much more of a state history.

Wisconsin may not have more history than Indiana, but it has more historians. Wisconsin is privileged to have a state historical society that is probably the best in the nation, and its university has been graced by a long line of distinguished American historians, beginning with Frederick Jackson Turner, the granddaddy of us all. On the basis of this tradition one might expect that the history of Wisconsin would be a major undertaking, and so it is. The State Historical Society of Wisconsin is publishing six massive volumes on the history of the state, two of which are under review here.

Volume three of the History of Wisconsin, by Robert C. Nesbit, covers the experience of the state during the crucial period of urbanization and industrialization in the late nineteenth century. Nesbit deals with Wisconsin chronologically under three broad topical sections that cover the economy, society, and politics and government. This is an impressive piece of scholarship. It is 
attractively produced and contains a large number of photographs, charts, and maps. Nesbit seems to exhaust most relevant Wisconsin sources and reaches conclusions that are wise and sensitive. His writing style is light and witty - even conversational with barbs sprinkled here and there, especially for Badger state politicians. He is strong on Wisconsin politics, and even stronger on the state's economy.

Despite its unquestioned strengths, though, Nesbit's volume has its weaknesses. It is, first, too Wisconsin-centered. Nesbit's discussion of Wisconsin society and demography would especially benefit from greater acquaintance with the findings of scholars who have studied other places: Readers will also find Nesbit repetitive. He covers particular developments, in education or politics, for example, in several different places, often in almost the same words. This goes to what I consider to be Nesbit's greatest shortcoming. His treatment of Wisconsin history during this period is simply too long, too detailed, and too self-indulgent. Extended discussions of such endeavors as dairying and lumbering are interesting enough, and enlightening, too, but are they really necessary? Is Nesbit's detailed examination of public issues and figures - more than twenty pages on Governor Jeremiah Rusk alone, for example - essential? The author thinks so, even complaining (on page 633, no less) that he lacks the space to explore fully the subject at hand! I think not.

In his volume on Wisconsin between 1940 and 1965, William F. Thompson exhibits all of Nesbit's vices but fewer of his virtues. That there are some of the latter here is undeniable. Thompson is an affectionate adopted son of the Badger state, and his regard for it and its people comes across clearly. His exploration of the position of blacks in Wisconsin and of their struggle for equality is thoughtful, sensitive, and even courageous. Thompson's discussion of politics - his area of greatest expertise - is instructive. Anyone wanting to know about the collapse of the Progressive party, the key to Republican dominance, the source of Joe McCarthy's local popularity, or the rise of the Democratic party to the status of a respectable opposition will learn a great deal from Thompson's book.

If Thompson's strength is political history, which it clearly is, then his weakness is social and economic history. His coverage of politics is chronological, while his discussion of society and the 
economy is more topical. That would be all right, except that it contributes to some indiscipline on his part, as when he discusses economic developments in the seventies and eighties, far beyond the stated termination of his volume. His remarks on Wisconsin society are especially disappointing. He considers social and demographic trends in the state as if it existed in a vacuum. He raises questions that he does not answer and floats theses on rafts of unsupported assumptions. His discussion of women is concentrated in a chapter on the home, as if women were confined to that institution and men and children had little to do with it. Throughout the volume there is irritating repetition and self-indulgent concentration on relatively obscure events and personalities. Just when the reader thinks Thompson has said everything that can be said about a particular point, the author gets a second wind and off he goes again. For nearly 740 pages the reader wonders when Thompson is going to cut to the chase. He never does, because there is no chase to cut to.

Nesbit and Thompson have displayed impressive knowledge of Wisconsin in these volumes, but they have produced books of limited value. If the other volumes in the series are like these, then what will have been produced is a compendious record of the state to which specialists in Wisconsin history can refer to get the definitive word on some particular detail or other. It is hard to imagine many students, or intelligent lay people, or even, truth be told, scholars reading all of these volumes. James Madison gave us a forest, while Robert Nesbit and William Thompson have reproduced many trees. As an outsider who is an expert in the history of neither state, I much prefer Madison's approach.

Richard Kirkendall's history of Missouri between 1919 and 1953 is a different matter altogether. Kirkendall organizes his book around Missouri's most famous citizen of this century, Harry Truman. The book opens with the year Truman returned to the state from France and concludes with his return to Missouri at the termination of his presidency. The organization of the book around Truman is curious and somewhat awkward. Because Kirkendall strives to cover social, cultural, and economic developments, Truman does not appear for long stretches. When he does appear, his presence sometimes seems rather artificial, and he occasionally detracts from the story Kirkendall has to tell. It is difficult to conclude, for example, that Truman's presidency really 
had all that much to do with Missouri as such.

A highly accomplished historian, Kirkendall generally tells the Missouri story well. His thesis is that during this period Missouri came to the realization that it was not to achieve the greatness it had foreseen for itself, especially in the American economy. This point is a bit forced, and advancing it leads Kirkendall to make some comparisons of dubious validity, but it is a generally convincing way of looking at the Missouri experience. There are some areas in which Kirkendall is an especially adept commentator. His coverage of the race issue and of urban problems in the Show Me state is admirable, as is his sensitivity to the suffering of Missourians during the depression. His grasp of culture from jazz music to baseball - is sure and quite impressive. He is excellent on politics. Indeed, his discussion of national politics is so full that he sometimes almost loses track of Missouri. Because he organizes topically within rather narrow chronological ranges he repeats himself to some extent, though not excessively.

One can be impressed by the performance of a polished professional and still come away dissatisfied. To my mind, Kirkendall is a bit too detached and too analytical. Madison loves Indiana - somebody has to, I guess - and Nesbit and Thompson love Wisconsin, but, despite his remarkable skills at analysis and synthesis, Kirkendall does not love Missouri. Consequently, he lacks the intuitive, emotional quality that sets historians apart from mere social scientists. The major result of his detachment is that we do not derive from Kirkendall the essence of the state's character and experience - what sets Missourians apart from other Americans, what they are like, what makes them like their state. Kirkendall's failure to give us a feel for the Show Me state, unfortunately, diminishes the value of the many admirable things he has done.

The good thing about all of these books is that they amply demonstrate the continuing vitality of state history. States may be mere political abstractions, of little significance in the larger national and international schemes of things, but historians persist in making them objects of analysis and even affection. There is something heartening in that. 
Copyright of Annals of Iowa is the property of State of Iowa, by \& through the State Historical Society of Iowa and its content may not be copied or emailed to multiple sites or posted to a listserv without the copyright holder's express written permission. However, users may print, download, or email articles for individual use. 